\title{
Exploring Various Promising Green Strategy for Recycling Spend Mushroom Substrate through Destop Research Analysis
}

\author{
Lydia N Horn ${ }^{1 *}$, Isabella S Ueitele ${ }^{1}$ and Mathew Nghifewa ${ }^{2}$ \\ ${ }^{1}$ Zero Emissions Research Initiative, Multi-disciplinary Research Center, University of Namibia, Namibia \\ ${ }^{2}$ Department of Biology, University of Namibia, Namibia
}

Submission: August 16, 2021; Published: September 07, 2021

*Corresponding author: Lydia N Horn, Zero Emissions Research Initiative, Multi-disciplinary Research Center, University of Namibia, Windhoek, 12007, Namibia

\begin{abstract}
Disposal of waste generated after the harvesting of mushrooms in one of the major problem in mushroom cultivation industries. There is an urgent need for a technology that produce high value products from spent mushroom substrate. This need came as a result of a huge amount of spent mushroom substrate produced by the edible mushroom industry which is on a increase in many countries around the world. If not well maintained, spent mushroom substrate could cause major environmental problem which is already felt in many mushroom producing countries. Most problems reported are associated lack of knowledge for treatment and disposal of spent mushroom substrate. Available information has revealed that many potential agricultural and industrial uses of spent mushroom substrate includes fertilizer manufacturing, animal feed, compost for the soil enrichment, treatment for coal mine drainage, bioremediation, enzyme extraction and novel bio-sorbent. This review aims at outlining some important techniques used in making use of the biological and agricultural waste emanating from mushrooms growing activities around the world. The review aims at availing some possible initiatives on reducing environmental waste through zero disposal of mushroom production waste while at the same time utilizing low value materials to produce value added products and generate income.
\end{abstract}

Keywords: Disposal of waste; Mushrooms; Organic materials; Lignocellulosic; Environmental pollution; Agaricus bisporus

\section{Introduction}

Mushrooms are macro fungi that produce fruiting bodies large enough to be seen with naked eye. During its growth, a mushroom can decompose organic materials such as maize and wheat. Mushrooms contain low fat and low cholesterol level and are used to treat patients with obesity and high cholesterol [1]. In addition, mushrooms are also high in fiber and contain essential amino acids. Edible mushrooms are cultured in media that usually consist of lignocellulosic agricultural waste such as crop straw [2]. According to Kulshreshtha [3], mushroom cultivation is regarded as an environmental approachable way to recycle wastes eminating from agricultural production and related activities. Appart from spent substrate, mushroom production bring about mushroom fruit bodies or mycelium which are regarded as good nutritive and medicinal produce. In addition, Langmuir isotherms reported of monolayer adsorption through mushroom fruit bodies or spent mushroom substrate [3]. Mushroom product has been on an increase and in Iran, mushroom production industries has been on a rise and were reported to be generating more than 50,000 tons of spent mushroom substrate annually substrate [3]. The generation of spent mushroom substrate was generally two times higher than the mushroom harvested. There is an urgent need to possibly make use of mushrooms spent substrate in order to curb environmental pollution. According to Cunha Zied et al. [4], making use of spent mushroom substrate is important because it allows a better use of the biomass which was meant for disposal but instead improved for energy efficiency and resource conservation. In 2016, market value of cultivated edible mushroom species is about $30-34$ billion dollars and medicinal mushroom species is 10-12 billion dollars. Production of medicinal mushrooms is regarded as one of the contributer to the increase of SMS. Large medicinal macro fungi companies in china such as Sanghuang which is one of the largest and most important groups of in traditional Chinese medicine for the past two centuries uses wood log for mushrooms production [5]. The cultivation of any 
mushroom strain results in the production of spent mushroom substrate which is high in organic matter, which according to Ma et al. [6], every kilogram of mushrooms produced emit about 6 $\mathrm{kg}$ of waste making it desirable for use as a soil amendment or soil conditioner. Valuable mushrooms such as Lentinula edodes and Ganoderma Lucidum are either cultivated on natural logs or on a synthetic medium formed in logs [7]. Substrate prepared specifically for growing mushrooms is a blend of natural products, for example at Zero Emission Research Initiative (ZERI) at the University of Namibia, the common materials used are maize, millet and wheat straws as well as woodchip [8]. Common ingredients used in other countries includes horse manure, hay, corn cobs, cottonseed hulls, poultry manure, brewer's grain, cottonseed meal, cocoa bean hulls and gypsum [9-11]. In some countries, spent substrate is spread in the field for one season to allow maturity, it is recommended that the aged spent substrate is good for soil improvement and crop growth. SMSs can also used as substrate for other mushroom forming fungi, animal feed and supplement and in the production of packaging and construction materials, bio-fuels and enzymes [1]. According to Chong \& Rinker [12] landscape and gardening companies uses spent substrate as the choice ingredient for potting mixtures sold in supermarkets or garden centers.

\section{Uses of Spent Mushroom Substrate}

One of the major environmental problems in the mushroom producing countries remains the treatment and disposal of the spent mushroom substrates (SMS). About $5 \mathrm{~kg}$ of SMS is produced for each kilogram of mushrooms [7]. According to Food and Agriculture Organization, (2007) Spain produces SMS of approximately 800, 000 tons per annum. SMS can be turned into compost and pit soil that can be sold to local supermarket, nurseries as well as vegetable gardens in the surroundings. Spent mushroom substrate were used as a source of immobilized mushroom mycelium, which is an efficient adsorbent of polluntants in mines and industry allowing $70-90 \%$ of pollutants removal [3]. According to Rinker [7], spent mushroom substrate has been used as an enzymes for bioremediation, animal feed, and energy feedstock. Bioremediation is the process whereby living organisms such as bacteria, fungi, or green plants are used to remove or neutralize unwanted contaminants in air, soil, or water. Oxidation of phenol by crude extracts of SMS from A. bisporus was reported and laccase was identified as the main enzyme responsible for the oxidation [13]. This means that Phenol and polyphenolic compounds which are toxic pollutants, representing a major organic component in some industrial wastewaters can be destroyed by using SMS [13] Frutos et al. [14] . Agaricus bisporus spent substrate has been used as component in the diet of carp [15]. Spent substrate were investigated in a study to degradation and remove pesticide in some areas and were found to be very effective in their application [16].
Besides the good effests SMS has also some negative effects attached to it. For example the SMS of Agaricus bisporus affecting health and producing odors after disposal because it continues to compost after production [13]. In addition some of the possible uses of spent mushroom substrates are summarised as follow.

\section{As a growing media for germination and growth of horticultural plants, soil improvement}

Mushroom cultivation is one of the environmental friendly ways to recycle agricultural and agro-industrial wastes for the production of mushroom [3]. A study by [17], demonstrated that SMS from Agaricus subrufescens that was used as soilbased potting to grow lettuce was high in organic matter and a good source of N, P and K. The aerial dry weight of the lettuce was higher compared to the dry mass of the lettuce grown from chemical fertilizer. From the same literature Lentinula edodes SMS a sterilized non-compost substrate with high $\mathrm{C} / \mathrm{N}$ presented a low degradation level and it is not suitable to be used as fertilizer unless $\mathrm{N}$ supplementation is used. Reported the effectiveness of MSM when used in the growing of cucumber (Cucumis sativus L. cv. Jinchun No. 2) and tomato (Solanum lycopersicum L. cv. Mandy) and results showed increased plant height, leaf area, fresh weight, dry weight and index of seedling quality grown in various ratios of SMS with perlite or vermiculite [18]. The use of immature compost increases microbial activity which causes oxygen deficiency as well as a variety of indirect negative effects on plant toxicity. Ribas et al. [17], recommended the use of fresh and untreated SMSs when used as a fertilizer and bioremediation agent simultaneously. Ribas et al. [17], further indicated that when SMS is without any heat treatment, it has the advantage of adding viable mycelia and several active enzymes produced by the fungus. Furthermore some SMS such as from L. edodes are used as fertilizer or soil conditioner, from the period of two months to two year of ageing because the salt content found in some fresh SMS may limits its immediate use as a growing media for plants [17]. Another way of using SMS is reuse in mushrooms cultivation as component of casing material or as supplement to new growth substrates in the new mushroom growing cycle [4].

\section{As a growing media for containerized woody ornamentals}

The SMS is formulated with lignocellulose materials from different sources such as wheat, rye or rice straw, sawdust and corncobs making it a great supplements to overcome nutritional limitations and to provide suitable substrate structure and $\mathrm{pH}$ for other crops to groe [18]. There is a new trend that replaces the current chemical adhesives with bio-based adhesives to reduce the use of toxic materials in the automotive and building materials. This is because new furniture releases formaldehyde levels up to more than $0.3 \mathrm{ppm}$ and this causes health problems [19]. Mycelium can be used as green adhesive material instead of the synthetic adhesive in wood production. The solid white mycelium will melt during hot-compression process and then 
penetrate to form tight nets of cohesion and incoherent material within the SMS matrix which enhance the adhesive and bonding resulting in a strong bio-composite [19]. In addition, these thick mycelium layers also showed good water resistance properties.

\section{As a source of clean energy}

The transition to bio-resource economy in a petroleum based economy is ideal by using renewable natural resources and adding value through biological life processes. In previous studies it shows that SMC such as straws can be combusted in a bubbling fluidized-bed to generate power with high efficiency [20]. Herrero-Hernández et al. [16] reported that SMS is the best suit for adsorption of pollutants which can be reused and recycled for the adsorption of pollutants as many times as possible by using different chemical treatments and by modifying it in activated carbon form. The spent mushroom substrate work by binding with positive charge metals whereby adsorbs metals which are present in the solution and involved in metal chelation $[3,21]$.

Woodchip-derived SMSs have a high moisture and oxygen content that result in low heat vale which is not suitable as bio-fuels. These materials cannot be burned as smokes from combustion of these materials that contain high lignocellulosic content are detrimental to the environment.

\section{As a source of construction and packaging materials}

Combustion of SMS leads to production of ash usually about $10 \%$ of its original value. This ash can be used as a chemical activator to enhance the pozzolanic reactivity of pulverized fuel ash in the cement industry [20]. According to Khoo et al. [19] the SMS is used in the formulation of bioblocks, and during hot-compression process, the solid white mycelium melt and then penetrate to form tight nets of cohesion and incoherent material within the SMS matrix which enhance the adhesive and bonding resulting in a strong bio-composite. The SMS have also been used in manufacturing of biodegradable bioblocks which is done using a green synthesis approach and the mycelium as a natural adhesive material [22]. Another way in which SMS was successfully used was the design and thermoforming of growth trays, tray sterilization, filling trays with mycelium inoculated substrates filling and allowing growth to occur, and after that, convection drying/inactivation of the grown parts follows [23]. According to Joshi et al. [23], the construction materials such as bioblock showed gread thermal stability, hydrophobic properties compined with mechanical strength. This could be great source of construction materials especially among poor resource farmers where the SMS is usually remain unutilized and contributing to environmental pollution. Various studies on the production of biodegradable and sustainable feedstock are on an increase, with the aim to replace petroleum-based materials commonly used for single- or multi-use packaging applications [24]. A study by Khoo et al. [19] reported on different types of spent mushroom substrates that were compressed with specific designed mould with optimal temperature at $160^{\circ} \mathrm{C}$ and $10 \mathrm{mPa}$ for $20 \mathrm{~min}$ to produce bio-boards. In addition, biobords made from Ganoderma lucidum SMS displayed the highest internal bonding strength up to $2.51 \mathrm{mPa}$ [19]. Among other importance of the SMS was the density profile which is very light, buoyant, and highly hydrophilic making it an idea material for both construction and packaging. R Ziegler et al. [24] further reported that the surface hardness test showed that the material has a soft outer surface with high elasticity. The SMS is also an ideal material for packaging applications due to its lightweight, resiliency, and biodegradability.

\section{Environmental rehabilitation}

Soil fauna contribute greatly to litter decomposition and soil organic matter stabilization. Protatia brevitansis is a soil dwelling insect [7]. Its larvae feed on large amounts of crushed straw and sawdust. This insect larva is commercially raised to produce high quality organic fertilizer and edible proteins. PB larvae can covert woodchip derived SMS and increase the total nutrient and seed germination index [1]. Cadmium metal is released by anthropogenic activities such as mining, phosphorus fertilizers and sewage irrigation. It is very toxic and is readily taken up by most plants [24]. Since L. edodes has the ability to improve microbial activity it may have an important role in bioremediation because it may harbor microbes that have the ability to degrade this heavy metal. Biochar is biomass pyrolyzed and it has been taken as the most effective organic amendment to immobilize heavy metals and improve soil quality, owing to its high alkalinity, large specific surface area, rich pore structure, and cation exchange capacity [25]. Overdose biochar will not only pollute the environment but also change the composition of soil material, which may affect the soil normal functions. To prevent these disadvantages, a combination of SMS and alkaline amendments may be a promising approach that compensates mutual functions. It has been reported that when lime is mixed with other organic amendments, soil $\mathrm{pH}$, electrical conductivity (EC), and precipitations of soluble ions might be further increased [25]. According to Udochukwu et al. [26]; Sriherwanto et al. [27], mushrooms can be served as green adsorbent which can accumulate pollutants from the surroundings and reduce their concentration. Since the mushroom mycelium can be used in the live or dead form, the SMS will be best suited to be used in the form of green adsorbed.

\section{Conclusion}

Based on the litreature research and information available, SMS could be a great resource for income generation once the equipment and technical know how is availed. Production of mushrooms cannot only result in the production of mushroom fruiting body but the byproduct are great source of building materials, organic matter and soil ammendment. This article was 
reviewing litreature to see the possible way in which SMS can be better utilized in Namibia and beyond.

\section{References}

1. Wei P, Li Y, Lai D, Geng L, Liu C, et al. (2020) Protaetia brevitarsis larvae can feed on and convert spent mushroom substrate from Auricularia auricula and Lentinula edodes cultivation. Waste Management 114: 234-239.

2. Dávila GLR, Murillo WA, Zambrano CJF, Suarez MH, Mendez JJA (2020) Evaluation of nutritional values of wild mushrooms and spent substrate of Lentinus crinitus (L.) Fr. Heliyon 6(3): 0-4.

3. Kulshreshtha S (2019) Removal of pollutants using spent mushrooms substrates. Environmental Chemistry Letters 17: 833-847.

4. Cunha Zied D, Sánchez JE, Noble R, Pardo Giménez A (2020) Use of spent mushroom substrate in new mushroom crops to promote the transition towards a circular economy. Agronomy 10(9): 1239.

5. Zhou LW, Ghobad Nejhad M, Tian XM, Wang YF, Wu F (2020) Current Status of 'Sanghuang' as a Group of Medicinal Mushrooms and Their Perspective in Industry Development. Food Reviews International, pp. 1-19.

6. Ma Y, Wang Q, Sun X, Wang X, Su W, et al. (2014) A study on recycling of spent mushroom substrate to prepare chars and activated carbon. Bioresources 9(3): 3939-3954.

7. Rinker DL (2017) Spent mushroom substrate uses. Edible and medicinal mushrooms: technology and applications Wiley, Hoboken, pp. 427-454.

8. Ueitele I, Kadhila Muanding N, Matundu N (2014) Evaluating the production of Ganoderma mushroom on corn cobs. African Journal of Biotechnology 13.

9. Girmay Z, Gorems W, Birhanu G, Zewdie S (2016) Growth and yield performance of Pleurotus ostreatus (Jacq. Fr.) Kumm (oyster mushroom) on different substrates. Amb Express 6(87): 1-7.

10. Hoa HT, Wang CL, Wang CH (2015) The effects of different substrates on the growth, yield, and nutritional composition of two oyster mushrooms (Pleurotus ostreatus and Pleurotus cystidiosus). Mycobiology 43(4): 423-434.

11. Vijaykumar G, John P, Ganesh K (2014) Selection of different substrates for the cultivation of milky mushroom (Calocybe indica P \& C). Indian Journal of Traditional Knowledge 13(2): 434-436.

12. Chong C, Rinker DL (2013) Use of Spent Mushroom Substrate for Growing Containerized Woody Ornamentals: An Overview. Compost Science \& Utilization 2(3): 45-53.

13. Phan CW, Sabaratnam V (2012) Potential uses of spent mushroom substrate and its associated lignocellulosic enzymes. Applied Microbiology and Biotechnology 96(4): 863-873.

14. Frutos AG, Eymar E (2010) Applicability of spent mushroom compost (SMC) as organic amendment for remediation of polluted soils. Acta Horticulturae 852: 261-268.

15. Sehgal HS, Simmi S (1991) Efficacy of two new supplementary diets for an Indian major carp, Cirrhina mirigala: effects on flesh composition. Journal of Aquaculture in the Tropics 6(1): 25-33.
16. Herrero Hernandez E, Andrades MS, Marın Benito JM, Sanchez Martın MJ, Rodriguez Cruz MS (2011) Field-scale dissipation of tebuconazole in a vineyard soil amended with spent mushroom substrate and its potential environmental impact. Ecotoxicology and Environmental Safety $74: 1480-1488$

17. Ribas L, De Mendonça M, Camelini C, Soares C (2009) Use of spent mushroom substrates from Agaricus subrufescens (syn. A. blazei, A brasiliensis) and Lentinula edodes productions in the enrichment of a soil-based potting media for lettuce (Lactuca sativa) cultivation: Growth promotion and soil bioremediation. Bioresource technology $100(20)$ : 4750-4757.

18. Zhang RH, Duan ZQ Li ZG (2012) Use of Spent Mushroom Substrate as Growing Media for Tomato and Cucumber Seedlings. Pedosphere 22(3): 333-342.

19. Khoo SC, Peng WX, Yang Y, Ge SB, Soon CF, et al. (2020) Development of formaldehyde-free bio-board produced from mushroom mycelium and substrate waste. Journal of Hazardous Materials 400: 123296.

20. Finney KN, Ryu C, Sharifi VN, Swithenbank J (2009) 'The reuse of spent mushroom compost and coal tailings for energy recovery: Comparison of thermal treatment technologies. Bioresource Technology 100(1): 310-315.

21. Javanbakht V, Alavi SA, Zilouei H (2014) Mechanisms of heavy metal removal using microorganisms as biosorbent. Water Sci Technol 69(9): 1775-1787.

22. Joshi K, Meher MK, Poluri KM (2020)Fabrication and Characterization of Bioblocks from Agricultural Waste Using Fungal Mycelium for Renewable and Sustainable Applications. ACS Applied Bio Materials 3(4): 1884-1892.

23. Jiang L, Walczyk D, McIntyre G, Bucinell R, Tudryn G (2017) Manufacturing of biocomposite sandwich structures using myceliumbound cores and preforms. Journal of Manufacturing Processes 28(1): 50-59.

24. R Ziegler A, G Bajwa S, Holt AG, McIntyre G, Bajwa SD (2016) Evaluation of Physico-Mechanical Properties of Mycelium Reinforced Green Biocomposites Made from Cellulosic Fibers. Applied Engineering in Agriculture 32(6): 931-938.

25. Jin Z, Zhang M, Li R, Zhang X, Wang G, et al. (2020) Spent mushroom substrate combined with alkaline amendment passivates cadmium and improves soil property. Environmental Science and Pollution Research 27(14): 16317-16325.

26. Udochukwu U, Nekpen BO, Udinyiwe OC, Omeje FI (2014) Bioaccumulation of Heavy metals and pollutants by edible mushroom collected from Iselu market Benin-city. Int J Curr Microbiol App Sci 3(10): 52-57.

27. Sriherwanto C, Purwaningsih RH, Yunita E, Sujai I (2021) Increasing the water stability of sinking feed grits using edible fungal hyphae for reducing aquatic waste: A laboratory study. IOP Conference Series: Earth and Environmental Science 744: 012079. 


\section{Your next submission with Juniper Publishers} will reach you the below assets

- Quality Editorial service

- Swift Peer Review

- Reprints availability

- E-prints Service

- Manuscript Podcast for convenient understanding

- Global attainment for your research

- Manuscript accessibility in different formats ( Pdf, E-pub, Full Text, Audio)

- Unceasing customer service

Track the below URL for one-step submission https://juniperpublishers.com/online-submission.php 